\title{
Treatment of Particulate Matter Pollution: People's Attitude and Readiness to Act
}

\author{
Vivita PRIEDNIECE ${ }^{1}$, Vladimirs KIRSANOVS ${ }^{2}$, Toms PRODANUKS 3 , \\ Ivars VEIDENBERGS ${ }^{4}$, Dagnija BLUMBERGA ${ }^{5}$ \\ ${ }^{1-5}$ Institute of Energy Systems and Environment, Riga Technical University, Azenes iela 12/1, \\ Riga, LV-1048, Latvia
}

\begin{abstract}
The paper displays results of the questionnaire called "Particulate matter pollution in air", which serves as a tool to determine level of public awareness of the health risks related to pollution from small capacity heating equipment in households. Barriers for installation of the innovative flue gas treatment technology called a fog unit in households and possible mechanisms to decrease or prevent these barriers were defined. The first part of the questionnaire included overall information about participants: age, gender, education level, place of residence, activities to protect the environment and motives behind performing these activities. The remaining questions were divided in four groups: "Environmental views", "Knowledge on air pollution", "Willingness to pay", "Choice of flue gas treatment technologies". The results of questionnaire correspond with raised problem situations. Over $80 \%$ of respondents lack information on pollution and possible consequences deriving from it, and on potential solutions to prevent pollution. Residents of households are willing to pay for installation of flue gas treatment equipment (capital investments).
\end{abstract}

Keywords - Emissions; flue gas treatment technologies; fog unit; multiple factor regression analysis; particulate matter; questionnaire

\section{INTRODUCTION}

In 2015 more than $45 \%$ of particulate matter (PM) emissions in Europe were created by small capacity combustion equipment. Studies conducted in China prove that biomass use in combustion equipment can make up 19\%-37\% from total PM amount, depending on weather conditions and seasonality, as well as biomass type [1], [2]. Particulate matter emission concentrations in air depend on many factors, including the topography of the area. This factor makes it difficult to develop a model for distribution in emission concentrations and forecast in air [3]. PM has negative effects on health starting from irritated eyes, nose and throat to reduction of lung function and life expectancy. Short-term exposure to PM exacerbates atopic dermatitis symptoms [4].

The Eco-design directive [5] states that starting from $1^{\text {st }}$ January 2020 each new heating and water heating appliance installed in households must be equipped with technologies to decrease particulate matter concentration in flue gases. One of the main goals of this directive is to provide that particulate matter emission concentration does not exceed $40 \mathrm{mg} / \mathrm{m}^{3}$ for boilers with automatic fuel feeding (for example, pellet boilers) and $60 \mathrm{mg} / \mathrm{m}^{3}$ for boilers with manual fuel feeding (for example, firewood boilers) [5].

\footnotetext{
* Corresponding author.
}

E-mail address: vladimirs.kirsanovs@rtu.lv 
An innovative technology for particulate matter emissions treatment has been developed in the Institute of Energy systems and environment at the Riga Technical University (Institute). It is called a fog unit - a flue gas condenser, meant for use after small capacity boilers in households that provides treatment of flue gases using the "fog effect" (small water drops $(\mathrm{d}<1 \mathrm{~mm})$ ). An additional advantage of this technology is recovery of heat, which in turn increases overall efficiency of the boiler. The efficiency of the fog unit reached in experiments is up to $15.39 \%$ (capacity $3.11 \mathrm{~kW}$ for pellet boiler with capacity $20 \mathrm{~kW}$ ) and the operating principle of the unit system is described in more detail in a paper by Priedniece et al. [6]. The use of a fog unit significantly decreases particulate matter amount in flue gases from combustion units, as shown by results described in [7], where PM reduction efficiency is from $28.6 \%$ to $77.3 \%$, depending on used nozzle type, sprayed water flowrate and other parameters. Integrating this device in households would lead to essential benefits both locally and globally, creating not only positive impact on the environment, but also on human health.

To define the level of awareness in society about flue gas pollution and its reduction technologies, a questionnaire called "Particulate matter pollution in air" was developed. In this case the questionnaire was used as a tool focused on solving two issues: first, the level of public awareness of the health risks caused by pollution from small-capacity heating equipment in households has been identified; second, possibilities and barriers for installation of the fog unit in households and potential mechanisms for reducing these barriers are defined. An on-line questionnaire was developed within the framework of the project of the fog unit [8]. Questions included in the questionnaire were developed, based on previous experiences related to questionnaires development in the Institute and examples in scientific literature, that are on similar topics.

In the paper of Decker T. and Menrad K. [9] the buying behaviour of homeowners regarding heating systems and choice of a certain one was researched. The study covered a part of private households in Germany. A questionnaire was used to obtain results, that were later analysed using multinomial logistic regression. Twelve of 29 different variables that effect the choice of certain heating systems proved to be statistically significant. These variables describe the owners of heat pumps, gas, oil and wood pellet heating equipment. Aspects effecting choice of the heating systems include comfort, ecological issues, technical description and issues, socio-demographic characteristics of the user, information, possible risks.

A study by Brutto et al. [9] focuses on integrating energy-efficient and modern appliances and technologies for biomass used as a source for energy production in Pakistan.

In another study respondents were sorted by their ecological attitudes: "environmentallyindifferent", "environmentally-nihilistic" consumers; ecologically-minded "active altruists", "active egoists" and "miserly pseudo environmentalists". Results of the study show that economic aspects are highly significant when buying oil and gas heating systems. Increasing direct subsidy payments for renewable heating systems could lead to increased use of wood pellet boilers and heat pumps in households. Another suggestion is to improve the marketing of renewable heating systems [10].

A different study by Rouvinen et al. [11] focused on the stated preferences of Finnish private homeowners for residential heating systems. The aim of the research was to determine how household owners' choice of heating system is affected by different factors of residential heating systems. The data was collected using a questionnaire by mail, that was sent out to random parts of Finnish private homeowners. The achieved response rate was $52 \%$ and the houses in focus were built in the timeframe of 1960-1990.

There were 6 alternatives offered for choice of a heating system: wood pellet, solid wood fired, oil boiler, district heat, electricity and heat pump with additional information, like investment and 
annual operating costs, $\mathrm{CO}_{2}$ and particulate matter emissions, required maintenance and additional work. District heat could only be considered, if the owner's house was located near existing heating network. To create an idea of effects, for example, of particle matter emissions on health, the questionnaire included additional information, like: if annual particulate matter emissions for a household are $2000 \mathrm{~g}$, then total emissions of several thousand similar houses can cause one premature death annually.

Obtained data were processed using the discrete choice experiment method, which uses the characteristic theory of value and random utility theory. It was assumed that the utility of homeowners was derived from heating systems characteristics. Results of the study show that costs are statistically significant factors for all alternatives. Maintenance work, additional work and $\mathrm{CO}_{2}$ emissions were statistically significant for all systems, excluding oil boiler and district heat. Particulate matter emissions are statistically significant for solid wood-fired equipment. The most preferred alternatives in the study were heat pumps and district heat [11].

The particulate matter emissions from biomass combustion in Madrid were studied and effects on people health were analysed by Linares et al. [12].

A study by Bjørnstad et al. [13] was conducted regarding household preferences of hybrid home heating systems using choice experiment. The results of the study were mainly targeted at policies, subsidies, taxes improvements and evaluation of existing policy. Overall, inhabitants have positive views regarding hybrid home heating systems, but effective information distribution and education mechanisms should be provided to enhance the ability to adopt innovative technologies in households.

A study by Wang et al. [14] described results of the survey conducted in northern rural China about cleaner heating choices to reduce air pollution in the area. The most popular heating method proved to be electric heating. The adoption of the heating methods increases with income level and the significant barriers are energy and device costs. Multinomial logit regression was the method used to analyse the data and showed that the most significant factors were income, heating area, cost of energy and education level. In this specific case, the gas substitution policy was more successful in enhancing cleaner heating methods than the electric substitution policy. Another fact proved by results was that people should have freedom to choose heating appliances and types and should have the necessary infrastructure available. Climate policy will play a significant role on the future development trend in China, including development and choice of heating system in households [15].

Research by Lillemo et al. [16] in Norway used an online survey to determine how household inhabitants' attitudes, motives, income and residence characteristics change possible investments in four types of different heating equipment: pellet and woodstoves, electric heaters and air-to-air heat pumps. It was found that people's perception about characteristics of the equipment (appearance, efficiency, investment and maintenance costs, required maintenance and time) and about environmental impacts caused are very different depending on the heating equipment. Another fact established during the survey was that over the last 10 years $52 \%$ of the households have invested over EUR 375 in heating equipment and $34 \%$ of these households have invested in at least two different types of heating equipment. The analysis of data obtained during the survey was performed using discrete choice models. Analysis showed that a household's willingness to invest and its choice of heating equipment is mostly affected by demographic parameters, characteristics of the residence, inhabitants' environmental attitude and motive. A study by Sopha et al. [17] also focused on Norwegian households, more closely on identifying factors that influence decisions made for buying a certain heating system. It emphasizes the need to 
differentiate policies for different groups of households and to consider region-related limitations. Fuel supply security and operational costs are significant factors affecting decision making in households.

\section{Methodology}

To improve the quality of the questionnaire, a consultation from Doctor of Social Sciences (Dr.sc.pol. - Doctor of Political Sciences) was received. The first version of the questionnaire was tested in the test group, that consisted of academic staff. After considering received suggestions, the questionnaire was improved and later published in the home page of the Institute: https://videszinatne.rtu.lv/ and shared using its social media accounts. The target group of the questionnaire is inhabitants from all regions of Latvia, covering different age groups and genders.

Inhabitants from different regions of the country took part in the questionnaire. The first part of the questionnaire included an overall description of participants: age, gender, education level, place of residence (region or city of importance of the Republic of Latvia), activities to protect the environment and motives behind performing these activities. 157 respondents took part in the questionnaire.

\section{Regression Analysis}

Multiple factor regression analysis was used to evaluate the data obtained with the questionnaire. Regression analysis describes interrelations between variables: how changes of independent variable $\mathrm{x}$ effect dependent variable $\mathrm{y}$. Regression can be portrayed as a linear function, with Eq. (1):

$$
y=b_{0}+b_{1} x+\epsilon
$$

where

$b_{0}$

$b_{1}$

$\epsilon$

free coefficient of the equation;

straight-line tilt coefficient. Both coefficients are obtained using calculations; case error [18].

It is necessary to define significance level boundary for eligibility of decisions, that in most cases is $p=0.05$ or $p=0.01$. This indicates, that one or many values from total number will not match with the hypothesis. Student's and Fisher coefficients are used to describe parameter set. There are variables that affect one another - changes in one variable affects the other variable. In this case, correlation exists between variables. This is described with a correlation coefficient, that represents the tightness of variables and is marked with $r$. Correlation can be positive, negative and it may not exist, if $r=0$. To determine the adequacy of the values obtained, regression analysis and statistical significance coefficient $t_{j}$, that is dependent of ratio of regression coefficient and corresponding Student's coefficient, were used [18].

$$
t_{j}=\frac{\left|b_{j}\right|}{S_{b_{j}}}
$$

where $b_{j}$ is regression coefficient, and $S_{b j}$ is mean square deviation of the regression coefficient. If obtained value is below the one shown in Student's coefficient tables, then the result is not valid. If the value is above the one in the table, then the obtained result is statistically significant.

Multiple factor regression analysis, that is included in the program Statgraphics Centurion XVII, was used for data evaluation. The selected regression type was Backward Stepwise Selection. 
It performs a backward stepwise regression, starting with a model that includes all variables. During the procedure, variables are removed one at a time, if they are not statistically significant. However, removed variables may also be added back to the model at later steps, if they become statistically significant. Overall in a stepwise regression, variables will be removed from the model at a given step if their $\mathrm{p}$ values are greater than the $p$-to-Remove value specified in the model, variables will also be removed from the model at a given step, if their F (Fisher coefficient) values are less than the $F$-to-Remove value specified

An example of the use of regression to analyse data obtained by questionnaires about consumers' willingness to adopt green electricity tariff, is found in research by Ozaki R. [19]. The results of the study showed that consumers need personal relevance to adopt green activities. Positive attitudes about environmentally beneficial activities do not mean that these activities are performed. To make adoption of green behaviour more enhancing, social norms must be considered. Changing tariff is time consuming and a considerably inconvenient activity due to new related works, changing costs and usability. The quality of the provided product is also an unclear factor. The main factors leading to switching to green tariffs are a mix of gained benefits, social influence and possibility to control expenses [19].

\section{RESUlts}

$54.1 \%$ of participants were women, $45.9 \%-$ men. About $80.9 \%$ of participants were in the age group from 20 to 45 years old, $5.1 \%$ were in the age group below 20 years, $10.8 \%$ were in the age group from 45 to 60 years and the remaining $3.2 \%$ were in the age group above 60 years. Education levels covered in the questionnaire were: higher education $(80.3 \%)$, secondary education ( $17.8 \%$ ), elementary education $(0.6 \%)$ and uncompleted elementary education (1.3\%). Participants' places of residence covered all regions and cities of importance of the Republic of Latvia. These territories are: Riga (the capital city of Latvia) and its' region (72\%), Vidzeme (8.3\%), Zemgale $(6.4 \%)$, Latgale $(5.7 \%)$, Kurzeme $(3.8 \%)$ and cities of importance $(3.8 \%)$. Cities of importance in Latvia are: Daugavpils, Jekabpils, Jelgava, Jurmala, Liepaja, Rezekne, Valmiera, Ventspils. Most of the participants of the questionnaire were from cities, therefore, results of the questionnaire can be mostly applied to the urban environment.

Eight activities for protection and prevention of the environment were offered in the questionnaire and a person could select more than one activity that he/she performs daily. The activities that are performed by over $50 \%$ of participants of the questionnaire were:

1. Saving energy (using economic lamps, electrical equipment, controlling electricity and heat use, etc., $87.9 \%)$;

2. Saving resources (re-use of products, using fabric shopping bags, etc., $79.0 \%$ );

3. Sorting waste $(58.6 \%)$.

There were five motives offered within these activities with an option to add your choice. The motives with agreement above $50 \%$ were:

3. Concerns about surrounding environment $(85.4 \%)$;

4. Concerns about the climate and the future $(67.5 \%)$;

5. Concerns about own health and those around them $(64.3 \%)$.

These results show that participants of the questionnaire are more interested in activities that are popularized more, with information about them available on different sources (media, internet, advertisements).

Remaining questions of the questionnaire were divided in four groups: "Environmental views", "Knowledge on air pollution", "Willingness to pay", "Choice of flue gas treatment technologies". Sections "Environmental views" and "Knowledge on air pollution" refers to all participants of the 
questionnaire, but the remaining two sections refer to those, that use combustion equipment in their households fuelled by firewood, pellets or another bioresource and that are affected by restrictions of the Eco-design directive [5].

The regression type Backward Stepwise Selection was used for every question group. It was estimated how evaluation of the question "Do you consider yourself to be a "green" thinking person?" ( $Y$, dependent variable) relates to changes in the statement group "Environmental views". Group "Environmental views" includes the following statements:

1. Ecological risks to population are often exaggerated;

2. Earth is like a spaceship with limited space and resources;

3. If people will live like before, we will experience major ecological disaster;

4. Nature will be able to provide equilibrium, to handle effects of modern industrial countries;

5. Population seriously endangers surrounding environment;

6. Environmental pollution can become a significant problem for You and Your family;

7. Environmental pollution will become a significant problem for our country;

8. Environmental pollution will become a significant problem for plant and animal species;

9. I have a personal commitment to do everything to prevent environmental pollution;

10. Entrepreneurs and industry must decrease the amount of emissions to prevent environmental pollution;

11. Government must act decisively to decrease emissions and prevent global environmental pollution;

12. I am well informed about air pollution;

13. I am well informed about flue gas treatment options.

Evaluation was given on a scale from 1 to 6 , where 1 - totally disagree and 6 - totally agree. Fig. 1. displays how many of the respondents agree with the following statements (value is over 3 ).

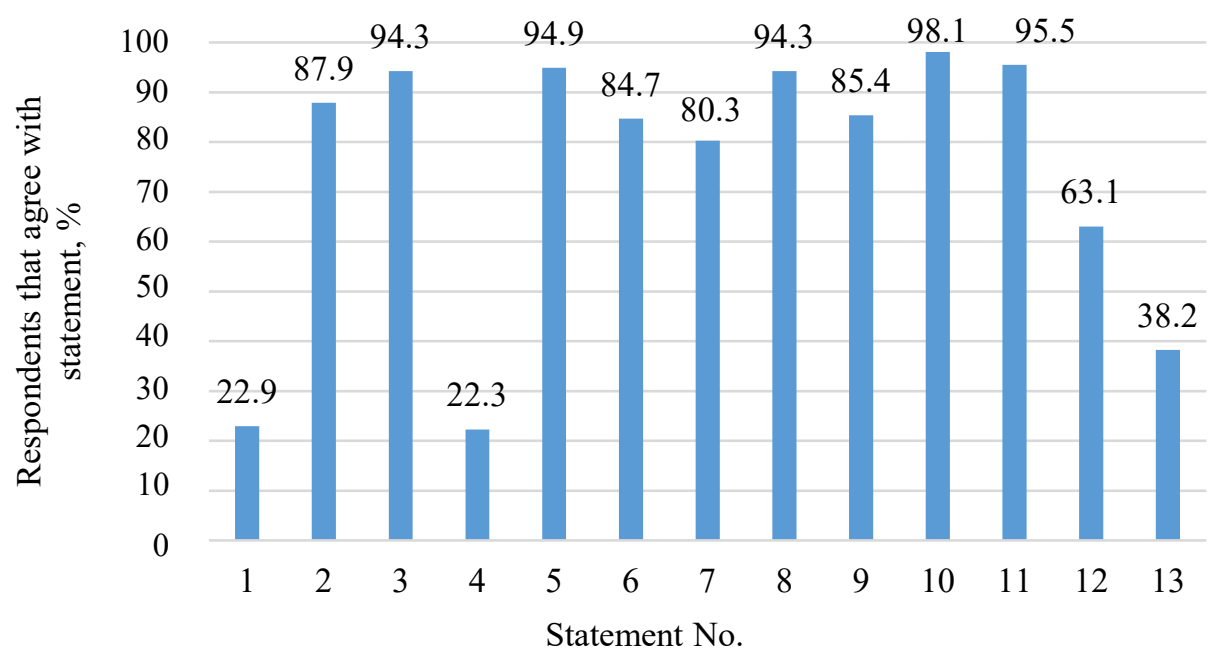

Fig. 1. Respondents that agree with statements in group "Environmental views".

Independent variables of the analysis, that are statistically significant, are values for statements: If people will live like before, we will experience major ecological disaster $(A)$; I have a personal 
commitment to do everything, to prevent environmental pollution $(B)$; I am well informed about air pollution $(C)$. The following equation is displayed below:

$$
Y=1.95017+0.170311 \cdot A+0.13725 \cdot B+0.213471 \cdot C
$$

Determination coefficient $\left(R^{2}\right)$ shows, that equation describes $19.04 \%$ from results with $95 \%$ statistical significance. Adjusted determination coefficient is $17.46 \%$ and standard deviation 0.92 . The obtained model describes the relation between question "Do you consider yourself to be a "green" thinking person?" and thirteen groups' "Environmental views" statements. From the analysed variables, three statements are statistically significant, that are shown in equation (their $p$ value is below 0.05 ). The determination coefficient for this analysis overall is low, which means that in the future this question should be studied in more detail, possibly dividing respondents in smaller groups or changing the formulation of the question itself.

The following regression analysis looked at the dependent variable - statement "It is necessary to solve problems related to air pollution from individual combustion equipment" (Z) evaluation changes depending on the statement values from "Knowledge on air pollution" group. Statements included in the group are:

1. There are harmful gaseous emissions in flue gases;

2. There are particulate matter (PM) emissions in flue gases;

3. Households are one of the main particulate matter emissions sources in Latvia;

4. Particulate matter emissions are harmful to human health;

5. There are problems with air pollution in my region;

6. I am worried about air pollution, that is created by my neighbours;

7. Flue gas treatment equipment must be installed in households.

Evaluation is given on a scale from 1 to 6 , where 1 - totally disagree and 6 -totally agree. Fig. 2 . shows how many respondents agree with certain statements (value is above 3 ).

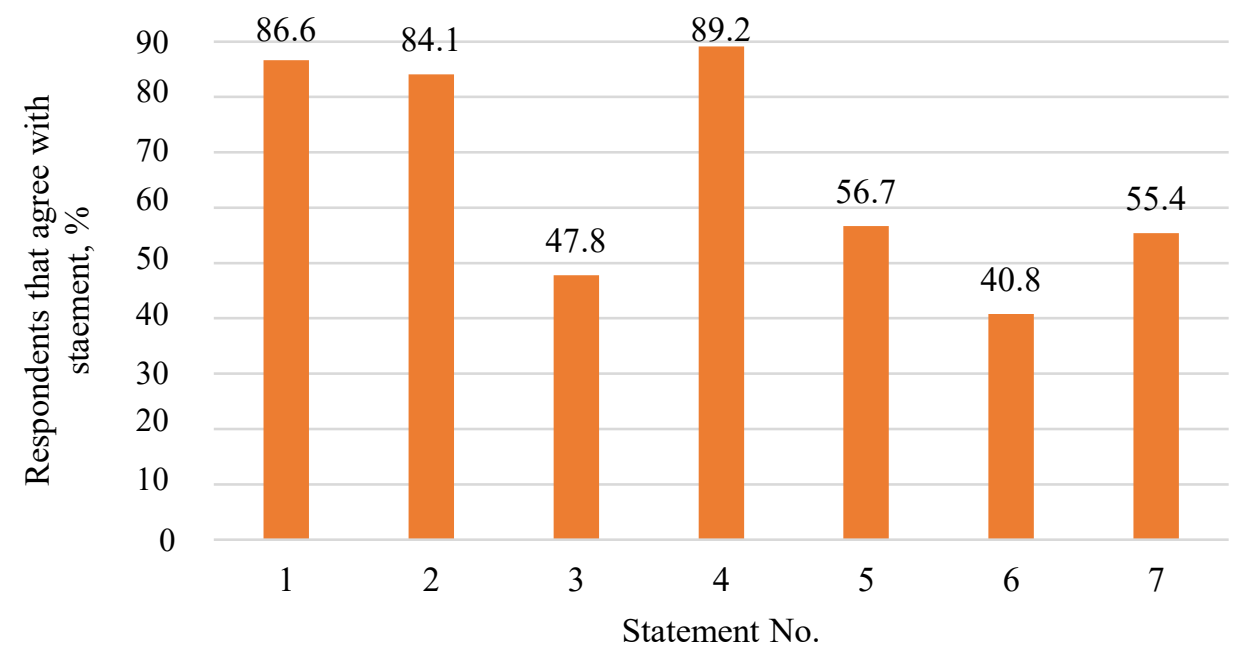

Fig. 2. Respondents that agree with statements in group "Knowledge on air pollution".

As a result of analysis, three questions (independent variables) were statistically significant: Particulate matter emissions are harmful to human health $(D)$; I am worried about air pollution, 
that is created by my neighbours $(E)$; Flue gas treatment equipment must be installed in households $(F)$. The describing equation is:

$$
Z=0.324587+0.172679 \cdot D+0.145407 \cdot E+0.612663 \cdot F
$$

Determination coefficient shows, that equation describes $59.88 \%$ from results with $95 \%$ statistical significance. Adjusted determination coefficient is $59.09 \%$ and standard deviation is 0.99 . Variables shown in the equation describe promoted statement "It is necessary to solve problems related with air pollution from individual combustion equipment" $(p<0.05)$.

Statements that respondents mostly agree on are: Particulate matter emissions are harmful for human health $(89.2 \%)$; There are harmful gaseous emissions in flue gases $(86.6 \%)$; There are particulate matter (PM) emissions in flue gases $(84.1 \%)$. All these statements have a value above 3 , which shows agreement with statements by more than $80 \%$ respondents. These results show that the participants in the questionnaire understand the issue of air pollution and their possible harmful effects on health. Another evaluation that has to be highlighted is that $47.8 \%$ of respondents agree that households are one of the main particulate matter emissions sources in Latvia. That is one of the factors that shows the lack of knowledge on particulate matter emissions and their effects on environment and human health.

Analysis of both question groups highlights the knowledge of inhabitants on air pollution and their concerns on providing quality of surrounding environment. Results of the second statement group, that are directly linked with particulate matter pollution and the necessity to prevent it, are particularly significant. There is a connection between pollution created by individual combustion equipment and the necessity to install flue gas treatment equipment, which means that society is aware of the problem and is open to search for solutions to it.

In the following parts of the study, attention was brought to participants of the questionnaire that use individual combustion equipment in their households. It focused on $51 \%$ of all respondents. However, this share of respondents was narrowed with the question "What kind of heat source is used in Your household?". The offered responses were: pellet boiler, firewood boiler, woodchip boiler, gas boiler, electrical boiler, firewood stove or furnace, heat pump and other (respondents can give their option).

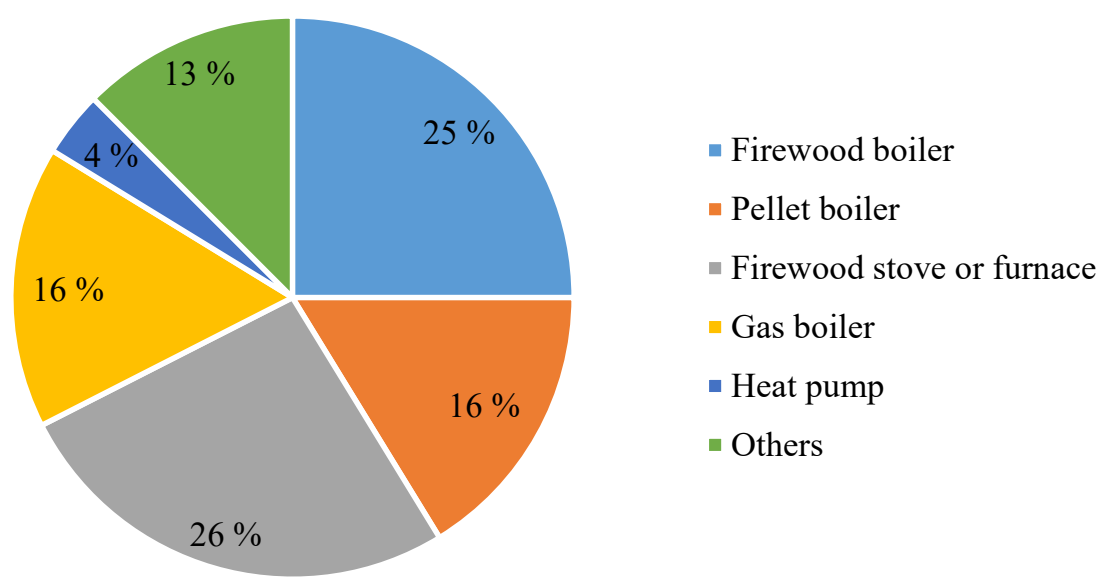

Fig. 3. Heat sources used in households by respondents. 
As can be seen in Fig. 3., the most widely used heating equipment between respondents was firewood furnace or stove $(26 \%)$, which is followed by firewood boiler $(25 \%)$, gas and pellet boilers (each $16 \%$ ), heat pump (4\%) and others (13\%). Woodchips boiler and electric boiler were not selected in the questionnaire. The options provided by the respondent under 'other' were combinations of several different equipment, coal boilers, fireplace and wood briquette furnaces. Combustion equipment chosen for further analysis were pellet boilers, firewood boilers and other equipment. This choice was made based on requirements of the Eco-design directive mentioned previously in this paper. This selection narrowed the number of respondents by $27.4 \%$.

The following paragraph includes boiler users' analysis, where the first step is to establish their knowledge level on flue gas treatment technologies (see Fig. 4.).

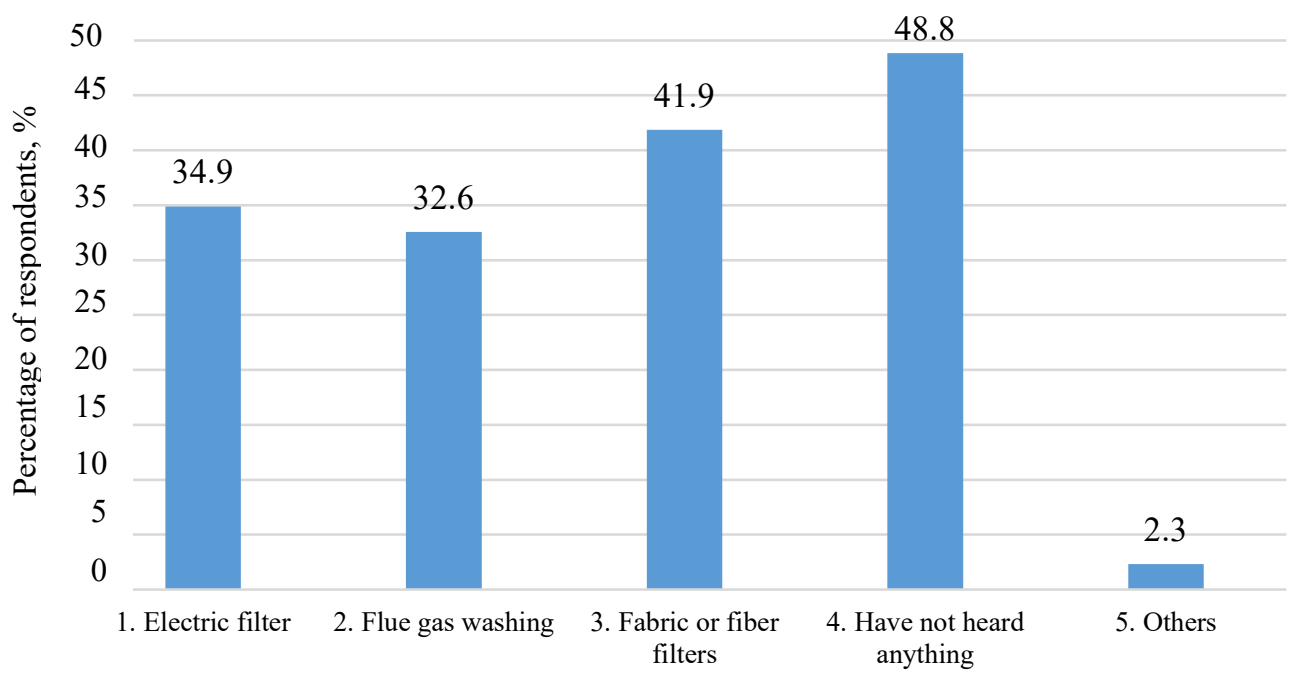

Fig. 4. Respondents knowledge on flue gas treatment technologies.

Respondents had a choice of five answers, of which in the fifth section "Others", it was possible to write in their own option. As can be seen in Fig. 4. the biggest part of respondents $-48.8 \%$ of combustion equipment users are not informed about flue gas treatment technologies. The remaining respondents are informed about at least one flue gas treatment technology. The best-known technologies are fabric or fiber filters, followed by electric filters and flue gas washing, but other technologies include cyclons, precipitators and filled chemical filters. The answers to this question highlight the lack of information in society about flue gas treatment necessity and options.

\section{Willingness to Pay for Flue Gas Treatment Technologies}

Multiple factor regression analysis studied how the statement "I would be willing to pay higher prices to live in clean environment" $(X)$ is affected by questions in the statement group "Willingness to pay". Statements included in the group are:

1. I would be willing to pay higher taxes to protect the environment (scale 1-6);

2. I would be willing to reduce my comfort level for the purpose of protecting the environment (scale 1-6);

3. I am willing to pay for the use of installed treatment equipment $\mathrm{EUR} / \mathrm{m}^{2}$ (considering area 
of the household), (scale $0-4)$;

4. I am willing to pay for the installation of flue gas treatment equipment (capital investments) $\mathrm{EUR} / \mathrm{m}^{2}$ (considering area of the household), (scale $\left.0-4\right)$.

Two questions were promoted as statistically significant (independent variables) as a result of the analysis: I would be willing to pay higher taxes to protect the environment $(G)$; I am willing to pay for the installation of flue gas treatment equipment (capital investments) $\mathrm{EUR} / \mathrm{m}^{2}$ (considering area of the household) $(H)$. The describing equation is:

$$
X=1.78262+0.500497 \cdot G+0.393921 \cdot H
$$

Determination coefficient shows that equation describes $57.22 \%$ of results with $95 \%$ stastistical significance. Adjusted determination coefficient is $55.08 \%$ and standard deviation is 0.89 . Results of this analysis show a positive trend in the respondent views, because in over $50 \%$ of cases inhabitants are willing to pay for installation of flue gas treatment equipment, however the negative side of this is that willingness to pay for the mentioned task does not prove to be statistically significant. People are not willing to reduce their comfort level, which is proved by the evaluation that $51.59 \%$ do not agree with that statement, therefore making it insignificant. Respondents' views on installation and expenses of flue gas treatment equipment is displayed in Fig. 5 and Fig. 6.

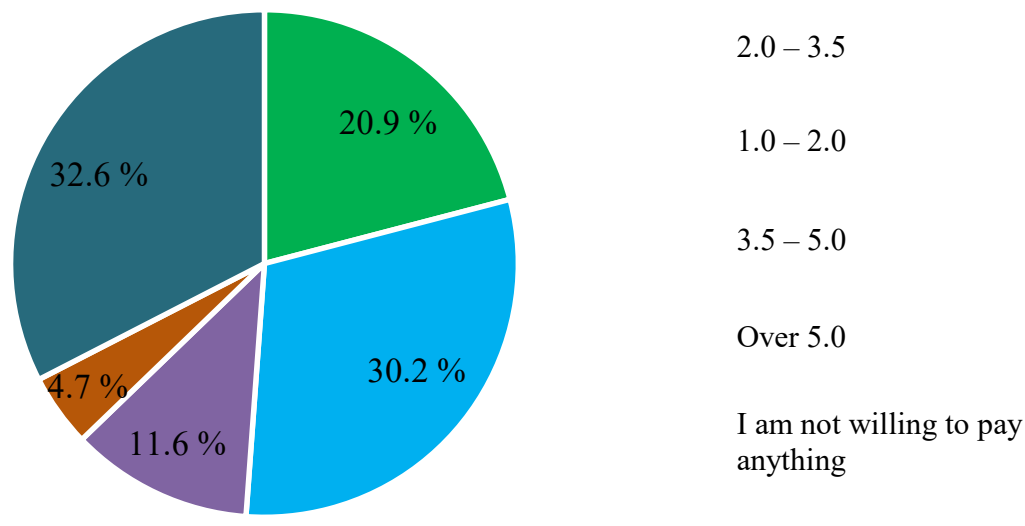

Fig. 5. Willingness to pay for installation of flue gas treatment equipment ( $F G T E$, capital investments), EUR $/ \mathrm{m}^{2}$ (considering area of the household).

As can be seen in Fig. 5, the the largest single proportion of boiler users (32.6\%) are not ready to pay anything for installation of flue gas treatment equipment. Still, the remaining $68.4 \%$ are ready to pay from 1 to more than $5 \mathrm{EUR} / \mathrm{m}^{2}$. This overview confirms results of multiple factor regression analysis, that capital investments needed for installation of flue gas treatment equipment is a significant variable. 


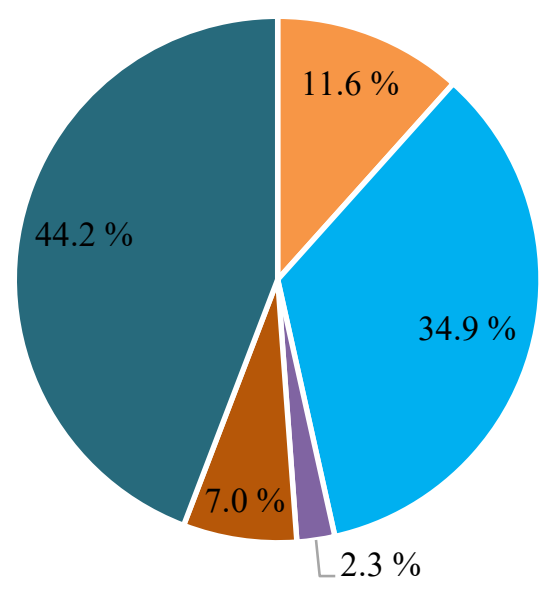

$0.5-1.0$

- $0.1-0.5$

- $2.0-5.0$

- $1.0-2.0$

- I am not willing to pay

Fig. 6. Willingness to pay for use of installed FGTE, EUR $/ \mathrm{m}^{2}$ (considering area of the household).

Looking at willingness to pay for use of equipment, the overview is different. $44.2 \%$ of boiler users are not prepared to pay for the use of flue gas treatment equipment. The biggest part $\sim 46.5 \%$ are ready to pay up to $1 \mathrm{EUR} / \mathrm{m}^{2}$, but only $9.3 \%$ of respondents are willing to pay over $1 \mathrm{EUR} / \mathrm{m}^{2}$. These results show that expenses, related to the use of flue gas treatment technologies, are a significant obstacle for installation of these technologies.

$48.8 \%$ of boiler users live in households with an area up to $100 \mathrm{~m}^{2}$, whereas in households with an area up to $200 \mathrm{~m}^{2}-39.5 \%$ and in households with an area above $200 \mathrm{~m}^{2}-11.6 \%$. In this case, the main factor is also the area of users' household. Depending on the household's area, monthly payments for equipment can be from approximately EUR 10 to over EUR 1000. Installation expenses can be from EUR 100 to over EUR 1000. Capacity of the combustion equipment changes depending on area of the household. Therefore, there might be a necessity to provide fog units of different capacities and sizes, creating increase in capital investments and monthly expenses, due to bigger sprayed water flows and an increase in electricity consumption. This question shows the necessity for low production expenses of the equipment, to provide as low as possible monthly expenses for households of any size. The recovery of latent heat that is provided by the fog unit leads to decreased heating expenses and fuel savings that makes this technology more attractive for use.

In addition, willingness to pay was also viewed from the perspective of gender, education levels, regions and age groups. From the gender perspective, women make up approximately $46.5 \%$ and men $-53.5 \%$ from the respondents in this part of the questionnaire. Women are willing to pay more for the installation of FGTE. When looking at willingness to pay about the use of FGTE, then an overall trend can be seen, that respondents are willing to pay more for installation of FGTE. In this case, men are more willing to pay from 3.5 to $5 \mathrm{EUR} / \mathrm{m}^{2}$, an equal number of respondents are willing to pay over $5 \mathrm{EUR} / \mathrm{m}^{2}$. Women are more willing to pay from 1 to $3.5 \mathrm{EUR} / \mathrm{m}^{2}$.

When looking at the use of FGTE, then women are more willing to pay for the mentioned service, however men are the ones who are willing to pay larger sums about it $\left(2-5 \mathrm{EUR} / \mathrm{m}^{2}\right.$ per month). Whereas, women are leading in other payment ranges. 
The following is an analysis on respondents' willingness to pay for FGTE depending on education level.

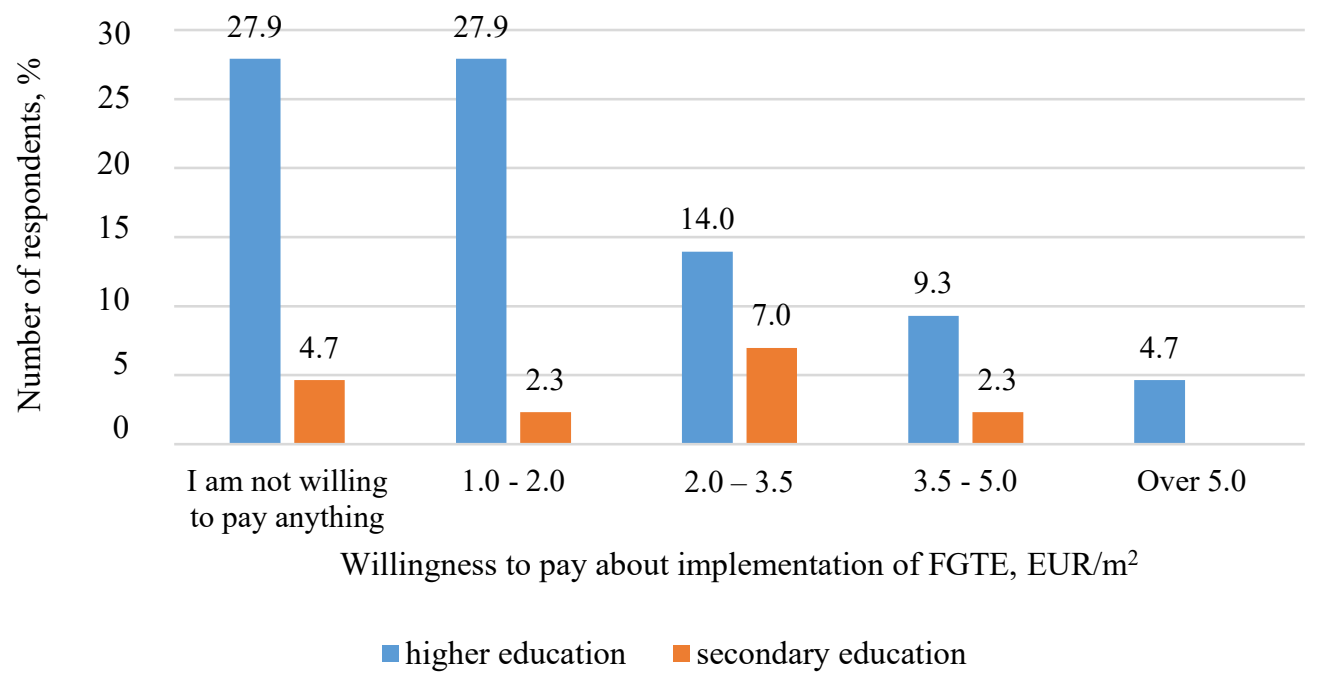

Fig. 7. Respondents' willingness to pay about installation of FGTE from education level perspective.

As can be seen in Fig. 7, the biggest part of respondents are with higher education. $27.9 \%$ of respondents with a higher education are not willing to pay for installation of FGTE, but the biggest part $-55.8 \%$ are ready to pay starting from $1 \mathrm{EUR} / \mathrm{m}^{2}$. Participants of the questionnaire with a secondary education are willing to pay from 1 up to $5 \mathrm{EUR} / \mathrm{m}^{2}$ for installation of FGTE. Other education levels were not respresented in this section of the questionnaire.

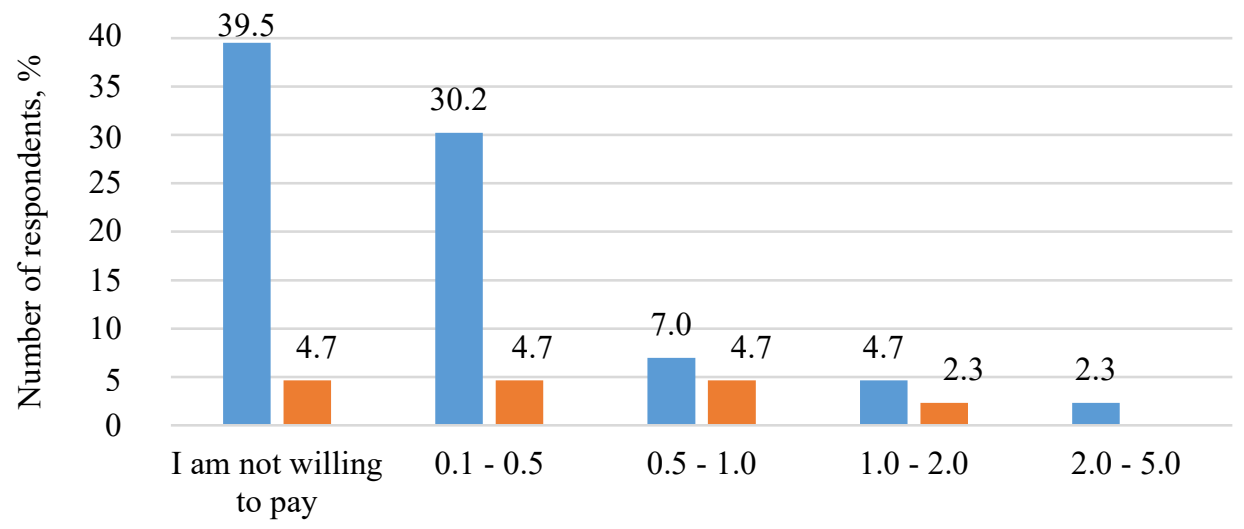

Willingness to pay about the use of FGTE, EUR $/ \mathrm{m}^{2}$ per month - higher education $\square$ secondary education

Fig. 8. Respondents' willingness to pay about the use of FGTE from the view of education levels. 
Moreover, respondents' willingness to pay for the use of FGTE from the education level perspective is lower. $39.5 \%$ of respondents are not willing to pay, but $44.2 \%$ are willing to pay for the use of FGTE to some extent. Participants of the questionnaire with secondary education are willing to pay from 0.1 up to $2 \mathrm{EUR} / \mathrm{m}^{2}$ for the use of FGTE.

Statement group "Choice of flue gas treatment technologies" followed evaluation of expenses. It included the following statements:

1. Equipment can not significantly increase electricity consumption;

2. Equipment must be compact;

3. Equipment must have simple maintenance;

4. It is a huge advantage, that equipment decreases fuel consumption;

5. The most important thing is flue gas treatment efficiency and pollution reduction;

6. The most important thing is installation expenses of the equipment;

7. The most important thing is total operating expenses;

8. The most important thing is easy collection of ash;

9. The most important thing is that collected ash is dry;

10. The most important thing is that collected ash is wet;

11. The most important thing is that my friends/acquaintances/neighbours know, that I use flue gas treatment equipment.

Statements evaluation was on a scale from 1 to 6 . Multiple factor regression analysis studied how the statement "It is important that no excess pollution is created" $(T)$ is affected by values of previously mentioned statements in the group "Choice of flue gas treatment technologies".

Results of regression analysis show, that values are statistically significant for statements: Equipment cannot significantly increase electricity consumption $(I)$; The most important thing is flue gas treatment efficiency and pollution reduction $(J)$. The describing equation is:

$$
T=1.09809+0.417561 \cdot I+0.3674 \cdot J
$$

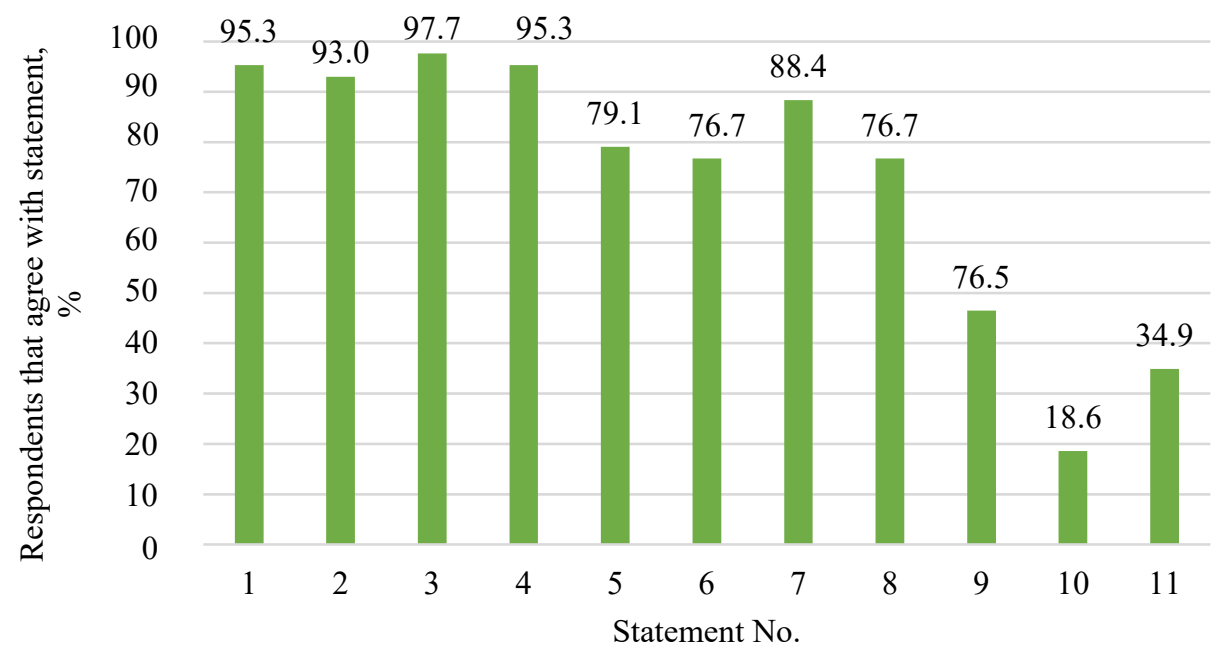

Fig. 9. Respondents that agree with statements in group "Choice of flue gas treatment technologies". 
From the group's "Choice of flue gas treatment technologies" statements, respondents mostly agree with those, that are related to maintenance and use of the equipment: Equipment has to have simple maintenance ( $97.7 \%$ ); Equipment cannot significantly increase electricity consumption $(95.3 \%)$; It is a huge advantage, that equipment decreases fuel consumption (95.3\%); Equipment has to be compact $(93.0 \%)$; The most important thing is total operating expenses $(88.4 \%)$. It points to the fact, that attention must be paid to providing optimal operation of the equipment.

Determination coefficient shows, that equation describes $30.48 \%$ of results with $95 \%$ statistical significance. Adjusted determination coefficient is $27 \%$, but standard deviation is 1.02 . This result shows, that appearance and maintenance of the equipment does not have primary significance, that at this moment allows to leave existing laboratory stand as it is. Significant parameters are electricity consumption and efficiency of the equipment, that are fixed during experiments. When optimal operation parameters will be found, it is planned to make an informative material, that contains information about operation regimes, capacity, energy consumption and required maintenance of the fog unit.

\section{Conclusions}

The developed questionnaire offers an insight into society's knowledge regarding air pollution and related problems. Participants from all regions of Latvia from different age groups took part in the questionnaire. The following conclusions are made from the analysis of results.

The question on environmental protection activitities highlights the fact, that respondents are carrying out activities that are promoted, with more available information in society. The first of performed multiple regression analysis for statement "Do you consider yourself to be a "green" thinking person?" shows that $19.04 \%$ of respondents agree with statistically significant statements: If people will live like before, we will experience major ecological disaster; I have a personal commitment to do everything, to prevent environmental pollution; I am well informed about air pollution. It leads to the fact, that over $80 \%$ of remaining respondents have lack of information on pollution and possible consequences of it, just as on potential solutions to prevent pollution.

Analysis of the question "It is necessary to solve problems related with air pollution from individual combustion equipment" highlights, that participants of the questionnaire perceive particulate matter emissions as harmful for human health and consider the installation of flue gas treatment equipment as a necessity in households. Similarly, a significant parameter is air pollution, that is created by surrounding inhabitants. Even though in the section of the questionnaire about flue gas treatment equipment and their choice options was filled out by a smaller number of respondents $(27.4 \%)$, an important problem was outlined. There is a lack of information in the public about flue gas treatment options and technologies.

The operating costs of flue gas treatment equipment is a problem, that might be related to households' area and the income level of inhabitants in households. Respondents are willing to pay for installation of flue gas treatment equipment (capital investments). To provide design and functions of the equipment, the main attention must be paid to electricity consumption and efficiency (treatment) of the equipment.

To describe the fog unit, an informative material, that will include information on equipment's operation regimes, capacity, energy consumption and required maintenance, will be developed. The fog unit provides low use costs and electricity consumption, that makes it attractive as flue gas treatment technology for use in households [20]. The results of the questionnaire correspond with the raised problem situations - level of public awareness of the health risks related to pollution from small capacity heating equipment in households and barriers for installation of the 
fog unit in households were defined, just as possible mechanisms to decrease or prevent these barriers.

\section{DISCUSSION AND FURTHER WORK}

The results of this study suggest some actions to improve information distribution in society about pollution. Unfortunately, it was determined that, at the moment, people are not ready to install flue gas treatment technologies in households, mainly due to economic aspects and lack of knowledge.

Also, there was no identified demand from the side of boiler manufacturers in the proposed flue gas purification technology. The main reason is the lack of demand at the legislative level and the fear of increasing the final price of heating systems. In this case, it is necessary to ensure awareness-raising measures in society on air pollution, particulate matter pollution, flue gas treatment options and technologies, as well as problems, that are related to these questions, using seminars, lectures, informative materials (posters, brochures, booklets), mass media. It is important to promote involvement of the Ministry of Environmental Protection and Regional Development of the Republic of Latvia in implementation of the Eco-design directive [5], to develop legal acts, that would provide the implementation of flue gas treatment technologies in households. Without legal acts that would make flue gas treatment in households' mandatory, it will be impossible to resolve the problem with PM pollution from households at this moment. It is because people are not willing to install flue gas treatment equipment voluntarily, even though they care about the environment and their health.

Possible improvements of the questionnaire could include additional questions regarding respondents' income, capacity of the used heating equipment and appropriate flue gas treatment equipment. Another change could be focus on inhabitants in rural areas of the country, as the income level and information distribution there is different, which might lead to different results regarding public awareness regarding air pollution and flue gas treatment options. Different aspects to be considered in the future research could be user behaviour regarding thermal energy consumption in households to identify possible improvements in combustion equipment performance [21].

Further work related to the fog unit includes determination of optimal operation parameters that would promote the development of descriptive informative materials for future users of equipment.

\section{ACKNOWLEDGEMENT}

The work has been supported by European Regional Development Fund project "Individual Heating with Integrated Fog Unit System (IFUS)" 1.1.1.1/16/A/015.

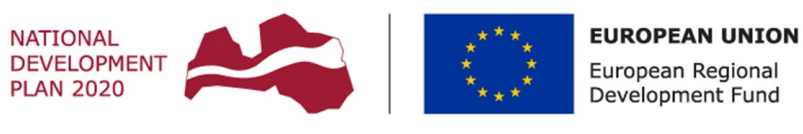

IN VESTING IN YOUR FUTURE 


\section{REFERENCES}

[1] Chen J., et al., 2017. A review of biomass burning: Emissions and impacts on air quality, health and climate in China. Science of Total Environment 2016:579:1000-1034. https://doi.org/10.1016/j.scitotenv.2016.11.025

[2] Clean Heat. Residential wood burning. Environmental impact and sustainable solutions. Berlin: Deutdche Umwelthilfe, 2016.

[3] Pereira G., et al. Development of a model for particulate matter pollution in Australia with implications for other satellite-based models. Environmental Research 2017:159:9-15. https://doi.org/10.1016/j.envres.2017.07.044

[4] Oh I., et al. Association between particulate matter concentration and symptoms of atopic dermatitis in children living in an industrial urban area of South Korea. Environmental Research 2018:160:462-468. https://doi.org/10.1016/j.envres.2017.10.030

[5] Directive 2009/125/EC of the European Parliament and of the Council of 21 October 2009 establishing a framework for the setting of ecodesign requirements. Official Journal of the Europeam Union 2009:L 285/10.

[6] Priedniece V., et al. Laboratory research of the flue gas condenser - fog unit. Energy Procedia 2018:147:482-487. https://doi.org/10.1016/j.egypro.2018.07.056

[7] Priedniece V., et al. Particulate Matter Emission Decrease Possibility from Household Sector using Flue Gas Condenser - Fog Unit. Analysis and Interpretation of Results. Environmental and Climate Technologies 2019:23(1):135-151. https://doi.org/10.2478/rtuect-2019-0010

[8] Fog unit (IFUS) | ENVIRONMENTAL SCIENCE [Online]. [Accessed: 17.10.2019]. Available: https://videszinatne.rtu.lv/en/science/project-and-research/fog-unit-ifus

[9] Bhutto A.W., et al. Promoting sustainability of use of biomass as energy resource: Pakistan's perspective. Environmental Science and Pollution Research 2019:26:29606-29619. https://doi.org/10.1007/s11356-019-06179-7

[10] Decker T., Menrad K. House owners' perceptions and factors influencing their choice of specific heating systems in Germany. Energy Policy 2015:85:150-161. https://doi.org/10.1016/j.enpol.2015.06.004

[11] Linares C., et al. Influence of advections of particulate matter from biomass combustion on specific-cause mortality in Madrid in the period 2004-2009. Environmental Science and Pollution Research 2015:22:7012-7019. https://doi.org/10.1007/s11356-014-3916-2

[12] Rouvinen S., Matero J. Stated preferences of Finnish private homeowners for residential heating systems: A discrete choice experiment. Biomass and Bioenergy 2013:57:22-32. https://doi.org/10.1016/j.biombioe.2012.10.010

[13] Bjørnstad E. Diffusion of renewable heating technologies in households. Experiences from the Norwegian Household Subsidy Programme. Energy Policy 2012:48(0301):148-158. https://doi.org/10.1016/j.enpol.2012.04.078

[14] Wang Z., et al. Cleaner heating choices in northern rural China: Household factors and the dual substitution policy. Journal of Environment Management 2019:249:109433. https://doi.org/10.1016/j.jenvman.2019.109433

[15] Woodward A., et al. Population health impacts of China's climate change policies. Environmental Research 2019:175:178-185. https://doi.org/10.1016/j.envres.2019.05.020

[16] Lillemo S.C., et al. Households' heating investments: The effect of motives andattitudes on choice of equipment. Biomass and Bioenergy 2013:57:4-12. https://doi.org/10.1016/j.biombioe.2013.01.027

[17] Sopha B. M., et al. Norwegian households' perception of wood pellet stove compared to air-to-air heat pump and electric heating. Energy Policy 2010:38(7):3744-3754. https://doi.org/10.1016/j.enpol.2010.02.052

[18] Esterkin P. I. Thermotechnical measurements in the combustion of gas and liquid fuels. Leningrad: Nedra, 1981. (in Russian)

[19] Ozaki R. Adopting sustainable innovation: What makes consumers sign up to green electricity? Business Strategy and the Envronment 2011:20(1):1-17. https://doi.org/10.1002/bse.650

[20] Priedniece V., et al. Sprayed Water Flowrate, Temperature and Drop Size Effects on Small Capacity Flue Gas Condenser's Performance. Environmental and Climate Technologies 2019:23(3):333-346. https://doi.org/10.2478/rtuect-2019-0099

[21] Jimenez-Bescos C., Oregi X. Implementing User Behaviour on Dynamic Building Silmulations for Energy Consumptions. Environmental and Climate Technologies 2019:23(3):308-318. https://doi.org/10.2478/rtuect-2019$\underline{0097}$ 